\title{
Nominal stress based equal fatigue bearing capacity design of HSLA steel V-shaped butt-welded joints
}

\author{
Xue Wen, Ping Wang, Zhibo Dong, Hongyuan Fang \\ State Key Laboratory of Advanced Welding and Joining, Harbin Institute of Technology, Harbin 150001, China
}

\begin{abstract}
Based on nominal stress, this paper proposed a fatigue life estimation method of V-shaped butt welded joints. Then, the fatigue bearing capacity of the base metal under the same fatigue load was used as design goal of the Vshaped butt welded joints and an equal fatigue bearing capacity (EFBC) design method for V-shaped butt welds was thus formed. High strength low alloy steel Q690 was chosen as the experimental material to carry out the equal fatigue bearing capacity design.
\end{abstract}

\section{Introduction}

With the continuous development of lightweight structures, the proportion of high-strength steel in mechanical structures is increasing [1-7]. High-strength low-alloy (HSLA) steel are widely applied in the fabrication of various structures, such as ship building, pressure vessel, offshore construction as well as submarine, owing to high strength, excellent toughness, and high strength-to-weight ratio. In welding HSLA steel, it imposes various problems, such as hydrogen-induced cracking, softening, and hardening of heat-affected zone (HAZ) because the steel is sensitive to thermal cycle $[8,9]$.

Under-matched welds are sometimes used in joining high strength steels with the aim of minimizing the hydrogen induced cold cracking tendency [10], reducing or even preventing costly preheating operations [11]. However, the low load carrying capacity of under-matched welds has been an obstacle to its wide engineering application [12, 13].

Currently, the fatigue design methods for welded structures given in various international standards include nominal stress method, structural stress method, effective notch stress method and fracture mechanics method [1417]. The global stress method (also known as the nominal stress method) is the most simple and widely used approach to design weldments against fatigue. When either nominal stresses cannot be calculated unambiguously or a reference fatigue curve for the specific geometry of the welded detail being assessed is not available, then either hot-spot or local stress based approaches are recommended to be used. The structural hot-spot stress method is applied by determining, on the component surface, the linear-elastic stress states at either two or three reference points. Subsequently, by using these reference stress states, structural stresses are extrapolated to the weld toes at the hot spots. Structural stresses can be determined experimentally by using strain gauges attached to the component's surface at different distances from the weld toe. Obviously, this experimental procedure is not applicable when the area of interest in the vicinity of the weld is not accessible. This problem can be overcome by estimating the stress states at the extrapolation points via linear-elastic Finite Element (FE) models. The hot-spot method was originally developed to assess the fatigue behaviour of offshore structures, with its use being subsequently extended to other structural applications. The effective notch stress approach makes use of linearelastic stresses determined at either the weld toe or the weld root by introducing a fictitious fillet having radius equal to $1 \mathrm{~mm}$, with this strategy being applicable to welded joints having thickness larger than (or equal to) 5 $\mathrm{mm}$. On the contrary, when the relevant thickness is lower than $5 \mathrm{~mm}$, the effective notch stress approach is recommended as being applied by using a fictitious radius of $0.05 \mathrm{~mm}$. This approach can be used to assess welded joint in which the fatigue crack initiation process takes place not only at weld toes, but also at weld roots [18]. Fracture mechanics may be used to assess the fatigue properties of welded joints in which no imperfections have been detected. In such cases it is necessary to assume the presence of an initial crack, for example based on prior metallurgical evidence, the detection limit of the used inspection method or fitting from fatigue data, and then to calculate the stress intensity factor [19]. However, whether the joint can have a fatigue bearing capacity not lower than that of the base metal through geometric design is yet to be studied.

From the stress-life curves of materials and structures, it can be seen that the fatigue life of materials and structures depends on the fatigue stress on their loadcarrying sections. For a certain external fatigue load, the fatigue stress value is determined by the size of the load bearing cross-section. Therefore, by changing the size of 
the load-carrying section of the structure, it is possible to develop the fatigue capacity of the structure. If we find the relationship between the size of the bearing section and the fatigue life of the structure, and then let the fatigue life of the structure equal to the fatigue life of the base metal under the same fatigue load, a weld structure with equal fatigue bearing capacity with the base metal can thus be obtained.

This paper starts from the perspective of structural safety and reliability, estimating the fatigue life of the $\mathrm{V}$ shaped butt-welded joint based on nominal stress. And then use the fatigue bearing capacity of the base metal under the same fatigue load as the design goal of the Vshaped butt welded joint. An equal fatigue bearing capacity design method for V-shaped butt welds was thus formed. High strength low alloy steel Q690 was chosen as the experimental material to carry out the equal fatigue bearing capacity design.

\section{Nominal stress based fatigue life estimation of V-shaped butt-welded joints}

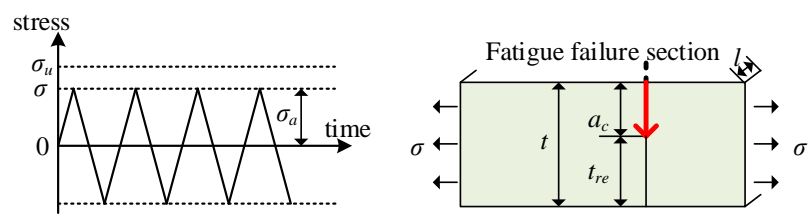

Figure 1. Fatigue failure process of homogeneous materials.

The fatigue failure process of homogeneous materials shown in Figure 1 can be described as: After the fatigue crack expand a certain length in the material, the stress value on the remaining bearing section of the specimen reaches the tensile strength $\sigma_{u}$ of the homogeneous material $[20,21]$, which leads to the instant rupture. The instant rupture section size $t_{r e}$ of homogeneous material can be approximated as:

$$
t_{r e}=\sigma \cdot t / \sigma_{u}
$$

For the case of fatigue stress ratio - 1 shown in Figure 1,

$$
\sigma=\sigma_{a}=P /(t \cdot l)
$$

From the fatigue failure process of homogeneous materials, it can be seen that the fatigue life of homogeneous materials $N$ corresponds to the number of stress cycles before the fatigue crack propagating to the instant rupture section $t_{r e}$. The dimension of the fatigue crack before extending to the instant rupture section can be referred to as the critical crack propagation size $a_{c}$.

$$
a_{c}=\mathrm{t}-t_{r e}
$$

To estimate the number of stress cycles experienced by fatigue cracks extending to a certain size in a homogeneous material, a traditional method is to first divide the fatigue failure process into three phases, namely the crack initiation phase, the crack propagation phase, and the instant rupture phase. Then use the material strain-life ( $\Delta \varepsilon-N_{i}$ ) curve to obtain fatigue crack initiation life $N_{i}$ $[22,23]$, and take the integral of Paris formula $[24,25]$ to calculate the number of stress cycles $N_{p}$ experienced by the fatigue crack when propagating to a certain size. Finally, add $N_{p}$ to $N_{i}$ to obtain the number of stress cycles experienced by fatigue crack when propagating to a certain size. The main problem of this method is that the definition of fatigue crack initiation is not uniform, which will bring certain calculation error, and it is inconvenient to use.

Since Wohler discovered the nominal stress-fatigue life (S-N) curve [26], it has undoubtedly become the most intuitive and effective way to characterize the fatigue properties of materials. Many researchers, including Wohler, summed up the functional relationship between nominal stress and fatigue life of homogeneous materials on the basis of a large amount of material fatigue data, and continuously improved it [27]. Most of the research results show that there is an exponential function relationship between the nominal stress on the load-bearing cross-section of the homogeneous material and the fatigue life in the highcycle fatigue stage, that is:

$$
(\sigma)^{m} \cdot N=C
$$

Where $m$ and $C$ are material related parameters.

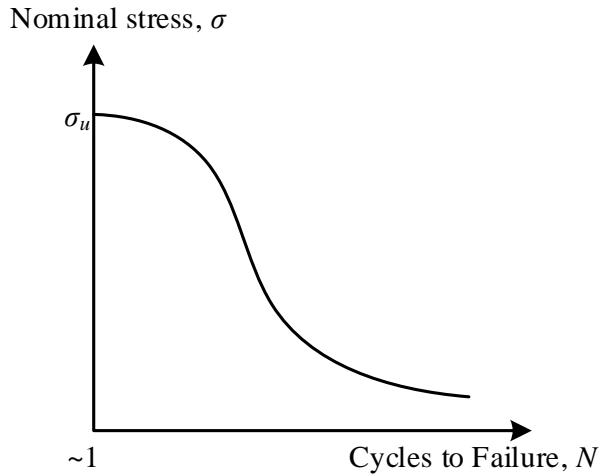

Figure 2. S-N curve of homogeneous materials

Based on nominal stress-fatigue life function of homogeneous materials, researchers can easily estimate the fatigue life of homogeneous materials under certain fatigue loads.

However, welded joints have heterogeneous mechanical properties and also exhibit highly heterogeneous microstructural variations in local regions[28-35]. Besides, due to the presence of the groove, the ratio of the base metal and the deposited metal on the fatigue bearing section of the welded joint is not a constant value. Therefore, the influence of the geometric size of the base metal and the deposited metal at the same fatigue bearing section on the fatigue life of the welded joint needs to be determined to achieve fatigue life estimation. This study found that the relationship between the geometric parameters of $\mathrm{V}$ shaped butt weld joints (as shown in Figure 3) and its fatigue life is as follows: 


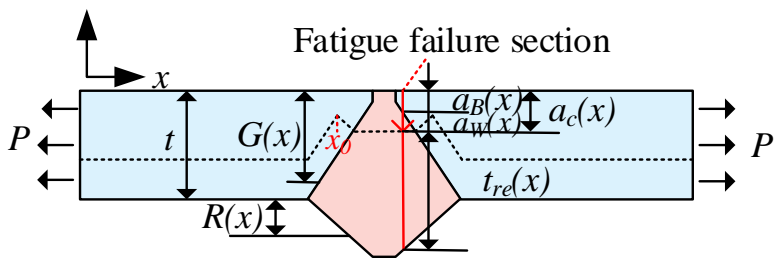

Figure 3. V-shaped butt-welded joint

$$
\begin{gathered}
N=\frac{C_{W} \cdot[t+R(x)-G(x)] \cdot[t+R(x)]^{m_{W}}}{\left[t+R(x)-\frac{P}{\sigma_{b}^{W} \cdot l}\right] \cdot\left(\frac{P}{l}\right)^{m_{W}}}+ \\
\frac{C_{B} \cdot\left[t+R(x)+G(x)-t_{r e}(x)\right] \cdot[t+R(x)]^{m_{B}}}{\left[t+R(x)-\frac{P}{\left.\sigma_{b}^{B} \cdot l\right]}\right] \cdot\left(\frac{P}{l}\right)^{m_{B}}}(5)
\end{gathered}
$$

Table 1 Main chemical composition and mechanical properties

\begin{tabular}{cccccc}
\hline Material & $\sigma_{y}(\mathrm{MPa})$ & $\sigma_{u}(\mathrm{MPa})$ & $\mathrm{C}(\%)$ & $\mathrm{Mn}(\%)$ & S-N formula \\
\hline Q690 & 720 & 788 & 0.14 & 0.13 & $\sigma_{a}^{11.1} \cdot N_{f}=6.38 \times 10^{33}$ \\
Welded metal & 450 & 647 & 0.06 & 6.39 & $\sigma_{a}^{11.1} \cdot N_{f}=7.16 \times 10^{32}$ \\
\hline
\end{tabular}

\section{Equal fatigue bearing capacity design of V-shaped butt-welded joints}

High strength low alloy steel Q690 was chosen as the experimental material to carry out the equal fatigue bearing capacity design. The main chemical composition and mechanical properties of the material are shown in Table 1. While $\sigma_{y}$ and $\sigma_{u}$ respectively refer to the yield strength and tensile strength of the material and S-N formula refers to the stress-life fitting formula of the material. The geometric parameters of the test plate and groove are shown in Figure 4.
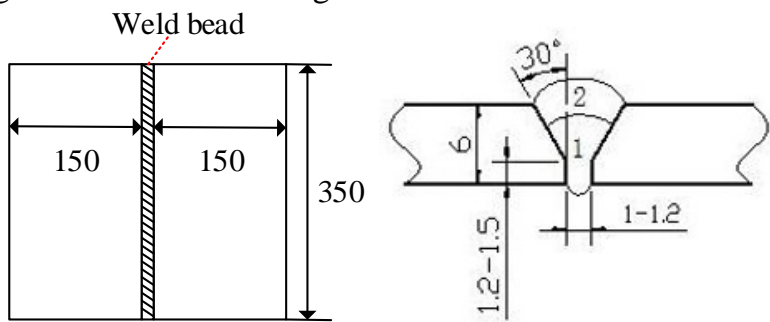

Figure 4. Geometric parameters of test plate and groove (mm)

The fatigue specimen of $\mathrm{V}$-shaped butt welded joint shown in Figure 5 is designed according to ASTM E46607 [36].

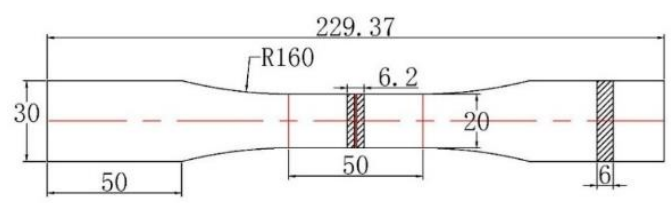

Figure 5. Fatigue specimen of V-shaped butt welded joint (mm)

$10^{4}$ stress cycles is used as the design goal of the Vshaped butt-welded joints, while the fatigue strengths of the base metal and the deposited metal are 484.3 MPa and 397.7 MPa, respectively, according to their S-N formulas. Substituting the known material and geometric parameters
The instant rupture section of the V-shaped butt-welded joint $t_{r e}$ in equation (5) is a piecewise function about the crack initiation position.

$$
t_{r e}(x)=\left\{\begin{array}{c}
\frac{P}{\sigma_{b}^{B} \cdot l}+\frac{R(x)-G(x)}{2}, x \leq x_{0} \\
\frac{P}{\sigma_{b}^{W} \cdot l}, x \geq x_{0}
\end{array}\right\}
$$

When the groove function $G(x)$, fatigue load $P$, and the mechanical parameters of the base metal and the deposited metal are known, the geometric dimension $R(x)$ of the double $\mathrm{V}$-shaped butt joint can be well-determined according to the EFBC realizing condition $N=N_{B}$. into equation (5), and then perform arc optimization on the resulting design curve. The final shape parameters of $\mathrm{V}$ shaped butt-welded joints are shown in Figure 6:

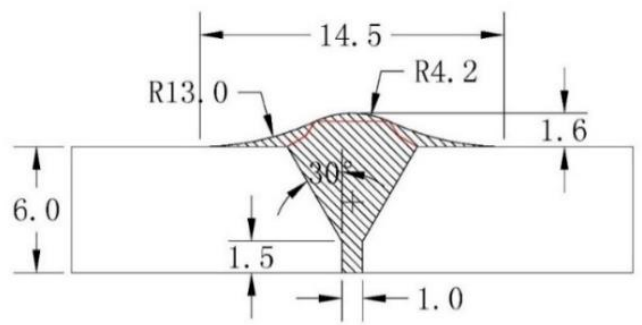

Figure 6. Designed V-shaped butt-welded joints (mm)

Due to the use of material's nominal stress-life formula in the design process, the $\mathrm{V}$-shaped butt-welded joint designed by this method is only applicable to experimental conditions when all hypotheses of the nominal stressfatigue life formula are satisfied.

\section{Conclusion}

With the aim of improving the fatigue load carrying capacity of under-matched V-shaped butt welded joints through structural geometric design. Base on nominal stress method, this paper proposed a fatigue life estimation method of V-shaped butt welded joints.

And then, the fatigue life of base metal under the same fatigue load was used as the design goal of the $\mathrm{V}$-shaped butt welded joints and an equal fatigue bearing capacity design method for $\mathrm{V}$-shaped butt welds was thus formed.

Finally, high strength low alloy steel Q690 was chosen as the experimental material to carry out the equal fatigue bearing capacity design, which showed that the proposed design method was theoretically feasible.

\section{References}


1. Cao X, Wanjara P, Huang J, et al. 2011. Mater. Des. 32(6):3399-3413.

2. Sterjovski Z, Dunne D, Ambrose S. 2004. Int J Press Vessel Pip 81(6):465-470.

3. Min D, Xin-hua T, Feng-gui L, Shun Y. 2011. Int J Adv Manuf Technol. 55(5-8):527-533.

4. Kim M-C, Park S-G, Lee K-H, Ho Kim S, Lee B-S. 2014. Curr Nanosci. 10(1):151-153.

5. $\mathrm{Xu} \mathrm{W} \mathrm{H,} \mathrm{Lin} \mathrm{S} \mathrm{B,} \mathrm{Fan} \mathrm{C} \mathrm{L,} \mathrm{et} \mathrm{al.} \mathrm{2014.} \mathrm{Int.} \mathrm{J.} \mathrm{Adv.}$ Manuf. Technol. 75(9-12):1439-1446.

6. Viano D, Ahmed N, Schumann G. 2000. Sci Technol Weld Join. 5(1):26-34.

7. Zhang C, Yang J, Hu X, Lu P, Zhao M. 2012. Mater Sci Eng A. 546:169-179.

8. Mohandas T, Madhusudan Reddy G, Satish Kumar B. 1999. J Mater Process Technol. 88(1):284-294.

9. Prasad K, Dwivedi D. 2008. Int J Adv Manuf Technol. 36(5-6):475-483.

10. Umekuni A and Masubuchi K. 1997 Weld. J. 76(7): 256s.

11. Loureiro and A. J 2002 J. Mater. Process. Tech. 128(1-3), 240-249.

12. Rakin, M., Medjo, B., Gubeljak, N.and Sedmak, A 2013 Eng. Fract. Mech. 109, 221- 235.

13. Zhu, L. and Tao, X. Y. 2016 Int. J. Pres. Ves. Pip. 139, 61-68.

14. Eurocode 3-Design of steel structures, Part 1. 8 Joints, EN 1993-1-8.

15. American Bureau of Shipping. Commentary on the guide for the fatigue assessment of offshore structures; January 2004-updated 2010.

16. BS5400, P. 10, 1980, Code of Practice for Fatigue. Steel, Concrete and Composite Bridges. British Standard Institution.

17. Eurocode 3-Design of steel structures, Part 1. 8 Joints, EN 1993-1-8.
18. Zamzami I A, Susmel L. 2016. Int. J. Fatigue. 101.

19. Hobbacher A. 2015. Springer.

20. Chandran, K. R. 2017. Int. J. Fatigue. 102: 261-269.

21. Chandran, K. R. 2015. Scripta Mater. 2015; 107: 115118.

22. Meggiolaro, M. A., \& Castro, J. T. P. 2004. Int. J. Fatigue. 26(5): 463-476.

23. Brennan, F. P. 1994. Int. J. Fatigue. 16(5): 351-356.

24. Paris, P. C., Gomez, M. P., \& Anderson, W. E. 1961.Trend in Engineering. 13.

25. Paris, P. C. 1963. Trans.asme Ser.d. 85(4): 528-533.

26. Suresh, S. 1998. Cambridge university press.

27. Castillo, Enrique, and A. Fernández-Canteli. 2009. Springer.

28. Kabir A S H, Cao X, Gholipour J, et al. 2012. Metall. Mater. Trans. A-Phys. Metall. Mater. Sci. 43(11):4171-4184.

29. Shen J J, Liu H J, Cui F. 2010. Mater. Des. 31(8):3937-3942.

30. Zhao Y Y, Zhang Y S, Hu W. E. 2013. Sci. Technol. Weld. Join. 18(7):581-590.

31. Li P, Dong H, Xia Y, et al. 2018. J. Manuf. Process. 33:54-63.

32. Mao Y, Ke L, Chen Y, et al. 2018. J. Mater. Sci. Technol. 34(1).

33. Chen J, Wei Y, Zhan X, et al. 2017. Int. J. Adv. Manuf. Technol. 92(2):1-10.

34. Magnabosco I, Ferro P, Bonollo F, et al. 2006. Mater. Sci. Eng. A-Struct. Mater. Prop. Microstruct. Process. 424(1-2): 163-173.

35. Liu H, Fujii H, Maeda M, et al. 2003. J. Mater. Sci. Lett. 22(6): 441-444.

36. Standard A. 2007. Standard practice for conducting force controlled constant amplitude axial fatigue tests of metallic materials. 3 . 